\title{
СТРУКТУРНО-СЕМАНТИЧЕСКИЙ АНАЛИЗ ФОТОТЕРМИНОЛОГИИ
}

\section{STRUCTURAL-SEMANTIC ANALYSIS OF PHOTOTERMINOLOGY}

\section{O. Kondratieva}

Summary: The paper introduces semantic topoi of phototerminology through its structural components. Semantic groups of temporality, locality, negation, intensification of qualities, reduction of qualities are shown to contain structures composed of classical elements, morphemes of Latin and Greek origin, both in English and Russian. Further research field is outlined as defining specific for photography semantic topoi: exposure, kinds of photography work and diditalisation of photographic processes. The paper draws some preconditions for archaic phototerminology to appear in response to nonlinguistic domain progression.

Keywords: terminological semantics, classical elements, structuralsemantic analysis, phototerminology.

\author{
Кондратьева Ольга Анатольевна \\ Аспирант, ГАО ВО «Московский городской \\ педагогический университет» \\ li-photo@yandex.ru
}

Аннотация: Материалы исследования раскрывают структурно-семантическую организацию терминологии фотографии. В статье представлен обзор семантических групп темпоральности, локальности, негации, усиления признака, ослабления признака на материале фототерминологии английского и русского языков. Обозначена область дальнейшего исследования специфических семантических групп, присущих данной области знания, в совокупности формирующих семантику профессионального поля фотографии. Сделан вывод о причинах формирования ряда архаизмов в фототерминологии.

Ключевые слова: семантика терминологии, греко-латинские морфемы, структурно-семантический анализ, фототерминология.

способов номинации [16], и структурно-семантических единиц фототехничекой терминологии [21]. Профессор С.В. Гринев-Гриневич акцентирует внимание на связи структуры термина и степенью развития терминологии и доказывает актуальность диахронических исследований отраслевых терминологий: «существует определенная связь между структурой терминов и временем их появления, а также между степенью развития области знания и средствами образования ее терминов. Все это свидетельствует о необходимости диахронического анализа отдельных способов образования терминов с учетом времени появления терминов, образованных этим способом». [4, с.122]. Анализ семантической структуры терминологической составляющей любого языка может оказаться полезным для понимания формирующейся структуры профессиональной области, смещения акцентов в ходе развития данной профессиональной области и причин формирования пласта архаизмов.

В целях данного исследования был подобран лексический материал на основе отраслевых изданий на русском языке [8, 13, 14, 19, 20, 23], использовались материалы англоязычных словарей: Cambridge [24], Longman [25], Meriam-Webster [26]; многоязычные интернет-ресурсы: multitran.com [27], The Free Dictionary [28].

Ученые выделяют два этапа в становлении предметной области: 1) начальный, естественный этап ее формирования и 2) сознательный, регулируемый. 
Первый этап связан с формированием новой области знания, с выделением научной компоненты новой сферы. В этот период появляется множество вариантов для обозначения одного и того же объекта, так как в основу обозначения разные исследователи-первооткрыватели данной области знания кладут разные признаки $[17$, с.15]. Наряду с синонимией неизбежно появляется функциональная полисемия, которая проявляется в перегруженности отдельных терминов и терминологических элементов различными значениями. Чаще многозначные слова обиходного языка приобретают новые значения в рамках формирующейся новой области знания.

В ходе проведенного исследования в английской ФТ были рассмотрены 632 фотографических термина и 698 русских фотографических термина. И в английской, и в русской ФТ доля однословных терминов составляет меньше четверти выборки. Среди однословных терминов принято выделять простые (корневые), чья основа совпадает с корнем $(R)$, производные (аффиксальные), чья основа содержит корень и аффикс/аффиксы $(R+s, p+R, p+R+s)$, и сложные, чья основа содержит несколько корневых морфем $(R+R)$. Обратимся к каждой из категорий.

Простые, или корневые, термины английской ФТ представлены существительными, прилагательными и глаголами. Доля простых терминов во всей выборке английских однословных фототерминов составляет 12\%: haze (блик), fog (вуаль), focus (фокус), lens (линза), angle (ракурс), raster (растр) и проч. Русские простые термины представлены такими терминами как бленда, блик, вираж, вуаль, кадр, кома, кофр, кювета, окуляр, ореол, фокус. Как видно, большая часть русских простых терминов образована путем калькирования и их доля в общей выборке - 7,5\%. Отдельно стоит упомянуть многозначные слова, которые приобрели новое специальное значение внутри ФТ: снимать [12], щелкать, печатать, ставить, линза, экспозиция и др. их доля невелика и содержит преимущественно глаголы.

Производные однословные термины в английской ФТ составляют треть от однословных терминов рассматриваемой выборки. Внутри данной категории английских терминов существует три словообразовательные модели:

1. суффиксальная, термины образованы по схеме $R+s$ (R- корень, s - суффикс);

2. аффиксальная, термины образованы по схеме $p+R$ (p - префикс, R - корень);

3. аффиксально-суффиксальная способ образования подразумевает наличие и префикса, и суффикса в структуре термина: $p+R+s$.

В группе производных однословных фототерминов можно выделить следующие семантические группы:
- группа терминов, репрезентирующих того, кто совершает действие, содержит окончание -er/or: sensor (сенсор), inhibitor (замедлитель процесса проявления), intensifier (раствор усилителя) restrainer (ослабитель раствора), polarizer (поляризатор);

- группа терминов, описывающих процессы, которые обычно в своей структуре содержат R+tion, R+ing, R+ise, $R+$ ment:

i. -tion: abberration (аберрация), sensibilization (сенсибилизация);

ii. -ing: backing (перенос отпечатка на постоянную основу), bracketing (брэккетинг/съемка со сдвигом в значении экспозиции), denoising (устранение шума), finishing (ретушь);

iii. -ise: sensitise (делать чувствительным к световым лучам, покрывать светочувствительным раствором);

iv. -ment: development (проявка);

- группа терминов, описывающих состояние, свойство и качество представлена терминами вида R+ity/ty, $R+c y, R+i c$ :

i. -y: intensity (оптическая плотность);

ii -су: transparency (прозрачность);

iii -іс: autotypic (автотипический), photographic (фотографический), panchromatic (панхроматический) и др.

В русской ФТ производные однословные термины составляют 80\% от всех однокомпонентных терминов, входящих в выборку. Результаты исследования формальноструктурной организации русской ФТ показали, что доля простых терминов составляет 24\% [11, с. 244].

Сложные однословные термины в английской ФТ могут быть написаны через дефис или слитно: представлены такими терминами как viewfinder (view+find+er) видоискатель, lightbox (light+box) лайтбокс, lenscap (lens+cap) крышка объектива и др.

В русской ФТ наблюдается значительное количество сложных однословных терминов, образованных путем слияния двух корневых основ $R+R$. Это обусловлено словообразовательными возможностями русского языка и тем, что подобный способ образования сложных слов привычен для носителей русского языка. Варианты перевода сложных корневых терминов профессионального поля фотографии сводятся к кальке и описательному переводу. Например, калькированием образованы такие термины как софтбокс, тильт-шифт, фишай, фотография. А видоискатель, широкоугольный, светопись были перенесены в русский язык путем перевода. Стоит отметить небольшое количество сложных однословных терминов, образованных путем слияния более, чем двух корневых основ, например, photomacrography (макрофотосъёмка), isopancromatic (изопанхроматиче- 
ский); actinic photometer (актинофотометр), monochromatic sensitometer (спектросенситометр), photoindustry (фomoannaратостроение).

Задачей данного исследования было установить связь между морфемами (в т.ч. греко-латинского происхождения) и семантическими группами, образующимися внутри ФТ при их использовании, а также выделить уникальные для данной профессиональной терминологии семантические группы. По словам В.Ф. Новодрановой греко-латинские морфемы «вступают между собой в синонимические отношения, образуют семантические группы». Ученый выделяет семантические группы темпоральности, локальности, негации, усиления признака, ослабления признака, родственной связи [17, с.46]. Проведенное исследование выявило, что помимо обозначенных В.Ф. Новодрановой семантических групп в ФТ наличествуют специфические семантические группы, присущие данной области знания и в совокупности формирующие профессиональную семантику фотографии: семантическая группа релевантности к фотопроцессам (фото- ), семантическая группа количества световых лучей, для получения фотоизображения (экспо-), семантическая группа фотохимии, семантическая группа множественности экспозиций (мульти-), семантическая группа дигитализации фотопроцессов (цифро-), семантическая группа видов съемки (микро-; макро-; аэро-; дрон-), которые представляют большой интерес и требуют отдельного подробного рассмотрения в будущем. В данной статье обратимся к основным семантическим группам, предложенных В.Ф. Новодрановой.

\section{Семантическая группа темпоральности}

К семантической группе выражающей темпоральность относятся термины с элементами instant, hour, synchro, chrono. Термин blue-hour (режимный свет/время), реферирует к определенной части суток - сумеркам - и подразумевает получение определенного эстетического эффекта. Компонент instant в термине instant photography, передает значение моментальности получения изображения, появившегося как результат преодоления недостатков ранних фотографичесих процессов, требовавших длинной выдержки. Термин появился в английском языке в 1937 г. с приходом компании Polaroid, предлагавшей альтернативный способ печати фотоснимков. Взрывной рост употреблений термина instant photography в ФТ и обиходном языке пришелся на 80-е гг. XX в. в связи с возросшей популярностью камер, производимых компанией Polaroid, которой удалось снизить стоимость расходных материалов и завоевать сердца потребителей. После появления цифровой фотографии термин instant photography стал использоваться меньше.

В русский язык термин моментальня фотография пришел позже по ряду экстралингвистических причин и кривая распределения частотности употребления данного термина имеет два пика: первый - появление термина в переводной профессиональной литературе, посвященной фотографии; второй - приход продукции компании Polaroid на постсоветский рынок. В английском языке фотокиоски обозначены термином photo booth, а в русском языке они продолжают называться моментальная фотография/моментальное фото, а фотокиоском считается специализированный стенд, оснащенный разъемами для считывания электронных карт памяти и монитором, подключенный к фотопринтеру.

Морфема synchro- образовывает обширную семантическую подгруппу «одновременности» и формирует значение соотнесенности моментов срабатывания разных частей фотоаппаратуры во времени: synchrotimer (таймер срабатывания затвора), synchronizer (синхронизатор), synchroterminal (синхроконтакт вспышки). Развитие технологий привело к появилению ядерный компонент семантического поля фотографии: синхронность процессов, синхронность работы элементовучастников фотосъемки.

Помимо перечисленных морфем, отражающих семантику темпоральности имеет морфема chrono-. Фиксация на одном отпечатке последовательных фаз движения путем производства съёмок с короткими равными промежутками времени называется chronophotography (хронофотография).

\section{Семантическая группа ^окальности}

Семантическую группу локальности в ФТ следует разделить на подгруппы:

1. семантика локальности процесса съемок;

2. семантика локальности (частей) аппаратуры относительно выделенного параметра,

3. семантика расположения внутри объекта (объектива, кадра, светочувствительной поверхности и т.д.).

Например, к первой группе будет относиться такие термины как indoor (интерьер, съемка в интерьере), outdoor (съемка вне помещения), ко второй - back (задняя стенка фотоаnпарата, цифровой модуль в модульных камерах), backing (фон для съемок), back/central/front lens (задняя/средняя/передняя линза объектива), back/front/ horizontal light (контровой/лобовой/боковой свет), а к третьей - TTL/through the lens (способ экспозамера через объектив), subbing (подсдлой фотографической эмульcuu).

\section{Семантическая группа негашии}

Семантическая группа негации в английской ФТ представлена терминами, образованными с помощью 
морфем a-, an-, anti-, de-, un-. В русской ФТ рассматриваемая семантическая группа образована терминами, содержащими морфемы: а-, ан-, анти-, де-, дис-, противо-. Отрицательная частица а-/an- входит в состав таких фототерминов как, например, aplanat (апланат), achromat (ахромат), afocal (афока́льная оптическая система), aspherical (асферическая оптика); anastigmat (анастигмат).

Морфема anti- (nротиво-) в ФТ на русский язык переводится тремя способами: первый - семантикой упреждения, т.е. слова, в состав которых входит данный префикс не всегда имеют однословный перевод, а переводятся выражением, например: antifoam (вещество, предупреждающее вспенивание фотораствора). Чаще применяется русский эквивалент приставки anti- противо-: antifoggant (противовуалирующее вещество); antihalation (nротивоореольность). Альтернативный вариант, который прижился в семантической группе «Объективы» - калькирование: antiplanat (aнmuпланат). Калькирование имеет экстралингвистические причины: объектив имел улучшенные свойства и быстро распродавался, его название вошло в профессиональную лексику без изменений из-за скорости распространения продукта. Далее конструкция данного объектива дала название целой линейке объективов, обладающих определёнными свойствами. В русской ФТ морфема анти- представлена малочисленными кальками антuблик, антипланат т.к. в основном термины с семантикой преодоления некоторого признака переводятся на русский язык морфемой противо-: противоореольный, противоскручивающий, противовуали-рующий или описанием.

Морфема de-(де-) в ФТ представляет группу терминов, показывающих отсутствие признака или действия, а также процесса обратного тому, который обозначен в корне термина: desalinization (опреснение), desensitising (десенсибилизация, понижение чувствительности), desolarisation (снижение эффекта соляризации).

Группа терминов, образованных с помощью морфемы un-: uncoated (непросветленный), undistorted (свободный от искажений), unexроsed (непроявленная или не отснятая пленка), unloading (извлечение кассеты), unsharpness (нерезкость). Термины данной семантической группы чаще всего переводятся описанием с использованием слов «свободный», «понижающий» или калькой с морфемами де-, не-.

\section{Семантическая группа ослабления признака}

Семантическую группу ослабления признака в английской ФТ представляют термины, образованные морфемой under-: underdevelopment (недопроявка), underехроsure (недодержка/недоэкспонирование). На русский язык данные термины переведены калькированием с использованием морфемы недо-. На раннем этапе формирования ФТ термины, содержащие морфему under-, переводились описанием, содержащим слово «недостаточный», ср. underdevelopment (недостаточная проявка), underexposure (недостаточное экспонирование). В настоящее время описательный вариант перевода терминов используется в официальных источниках (инструкциях и развернутых отчетах), а в профессиональном языке закрепился более короткий и удобный однословный эквивалент.

\section{Семантическая группа усиления признака}

Семантическую группу усиления признака образуют термины, образованные с помощью морфем ultra-, super-, pan-, hyper-. В английской ФТ данная группа представлена такими терминами как ultraspeed (сверхчувствительный, ультраскоростной), ultrathin (сверхтонкий). Отдельно следует рассматривать термин ultraviolet (ультрафиолетовый), раскрывающий другое значение морфемы ultra- «находящийся за пределами» видимого излучения. Термины, образованные морфемой pan-, подразумевают охват полного диапазона: panchromatic (панхроматический) т.е. охватывающий/реагирующий на все лучи видимого спектра фотоматериал. Морфемой super- образованы такие термины, как supercoating (защитный желатиновый слой), superimposing (многократное экспонирование), Superpan (негативная суперпанхроматическая плёнка).

Уникальные свойства, присущие фотографии, отображены в семантических группах, передающих семантику получения изображения на светочувствительной поверхности. Основная группа образована терминами с морфемами фото- и экспо-.

Сокращение от photography $\rightarrow$ photo $\rightarrow$ foto (фomozpaфия $\rightarrow$ фото) со временем стало графическим отражением сущности технологии получения изображения на светочувствительной плоскости и пережило превращение в морфему-префиксоид [18, с.53] со значением «фотографический, имеющий отношение к фотографии». Морфема фото- является центральной, ядерной, смыслообразующей в данной терминосистеме, соответственно, требует отдельного внимания.

В русском языке производительность морфемы фото- превосходит свой английский эквивалент photoчто объясняется тем, что данной морфемой переведены не столько термины, образованные по типу photo $R$, но и двусоставные термины вида photographic $+N$, а так же однословные термины не содержащие в английской версии морфемы photo-. 
Термины, образованные морфемой helio-/(гелио-), на данный момент можно причислить к фотоархаике, поскольку данная морфема использовалась на раннем этапе формирования ФТ и позже была заменена на морфему фото-: heliography (гелиография) $\rightarrow$ photography (фотография), heliogravure (гелиогравюра) $\rightarrow$ photogravure (фотогравюра), heliotype (гелиотипия) $\rightarrow$ phototype (фomomunuя).

Группа терминов номинирующих способы получения изображения, которые в своей структуре содержат $R+$ type, $R+$ graphy может быть отнесена к семантической группе релевантности к фотопроцессам в ФТ: daguerreotype (дагерротипия), talbotype (тальботиnия), суаnotype (цианотипия), stereotype (сmереonapa), stereography (стереография) и др. Стоит отметить, что данная категория терминов содержит максимальное количество эпонимов, которые к 1970-ым годам перешли в разряд архаизмов, т.к. номинируют ранние фотографические процессы. Внимание к данным терминам было привлечено при попытке воссоздания художественного эффекта, получаемого данными фотопроцессами цифровыми технологиями и при создании электронных архивов фотографического наследия в начале XXI века.

Исследователи ФТ указывали, что XIX век отмечен полным отсутствием эмоционально-экспрессивной окраски и предполагает, что «значительно большую часть современного словаря составляют слова, возникшие в первой половине 20 века.» [18 с.53]. Однако в указанной работе не были учтены изменения последних десятилетий, которые произошли в терминологии фотографии. После прихода цифровой фотографии значительную часть ФТ составляют слова современные, относящиеся к компьютерным технологиям и сфере социальной функции фотографии.

\section{Выво $\Delta ы$}

Анализ морфологии и семантического состава однословных терминов профессионального поля фотографии показал, что помимо выделенных ранее семантических групп темпоральности, локальности, негации, усиления признака, ослабления признака, родственной связи, в ФТ следует особо рассмотреть специфические семантические группы, присущие данной области знания и в совокупности формирующие профессиональную семантику фотографии. Греко-латинские морфемы используется во многих профессиональных областях и слова, содержащие данные элементы легки для восприятия и интерпретации, что является важным в терминотворчестве т. к. влияет на восприятие профессионалами, дальнейшее использование и создание терминологических гнезд. В терминологии фотографии используется большое количество греко-латинских морфем. Особенностью словообразования однословных терминов ФТ является наличие перешедших из химии, оптики и искусствоведения терминов, которые сохранили свойства исходных терминологий, наличие сложных однословных терминов из двух и более корневых основ. Переход ядерных терминов фотография и экспозиция в морфемы с более высоким словообразовательным потенциалом в русском языке, чем в английском связан с реализацией принципа языковой экономии. На русский язык фототермины переводятся калькированием в случае, если технология или явление проникают в профессиональный оборот очень быстро, переводом и описанием, если получившаяся калька не отображает необходимого содержания термина. Архаизмы в ФТ стали формироваться под влиянием процесса перехода на цифровые технологии и неизбежной смены устаревших явлений в профессиональном языке на новые, более современные. Рассмотрение данных процессов требует отдельного пристального внимания.

\section{ЛИТЕРАТУРА}

1. Асадова А.Ю. Структурно-семантическая характеристика многокомпонентных терминов (на примере терминологии цифровой фотографии) // Профессиональная коммуникация: актуальные вопросы лингвистики и методики. 2016. № 9. С. 30-37.

2. Вертьянова 0.В. К вопросу об особенностях английской туристической терминологии: на материале формально-структурного анализа // Коммуникативные исследования. 2019. Т. 6. № 2. С. $332-345$.

3. Володина М.Н. Теория терминологической номинации. - М. Изд-во МГУ, 1997. - 180 с.

4. Гринев-Гриневич С.В. Терминоведение: учеб. пособие для студ. высш. учеб. Заведений / С.В. Гринев-Гриневич. - М.: Издательский центр «Академия», 2008. - 304 c.

5. Гурьянова 0.А. Гиперо-гипонимические отношения в английской терминологии телевидения // Филологические науки. Вопросы теории и практики. Тамбов. Грамота, 2019. Т. 12. № 7. С. 180-184.

6. Долгоновская Л.Я. 06 особенностях терминосферы «информационная безопасность» // Успехи современной науки и 0бразования. 2017. Т. 5. № 3. С. 99-101.

7. Жаханова 3.Р. Структурно-семантические особенности многокомпонентных терминов в современном русском и английском языках на материале подъязыка архитектуры и строительства // Проблемы истории, филологии, культуры. 2015. № 2 (48). С. 274-279.

8. Жолудев Н. Композиция в фотографии. - М.: Эксмо, 2012. 272 с.

9. Ивина Л.В. Лингво-когнитивные основы анализа отраслевых терминосистем (на примере англоязычной терминологии венчурного финансирования): Учебно-методическое пособие. - М.: Академический Проект, 2003. - 304 с. -(«Gaudeamus»). 
10. Кондратьева 0.А. Диахронический анализ глагола снимать в значении фотографировать. // Вестник МГОУ. Серия: Лингвистика. 2020. №2. С.6-12.

11. Кондратьева 0.А. Формально-структурный анализ русской фототерминологии //Филологические науки. Тамбов: Грамота, 2020. Т. 13. Вып. № 11. С. 243-247.

12. Кубрякова Е.С. Основы морфологического анализа: на материале германских языков / Е.С. Кубрякова. - 2-е изд. - Москва: URSS, 2007. - 320 с.

13. Лапин А.И. Фотография как... Учебное пособие. -М.: Изд-во Московского университета, 2003. - 296 с.

14. Левашов В. Лекции по истории фотографии / Галина Ельшевская. 2-е изд. М.: «Тримедиа Контент», 2014. - 464 с.

15. Матвеева Е.Е. Лингвокультурологические особенности формирования лингвистической терминологии (на материале английских и русских терминов фонетики) диссертация ... кандидата филологических наук : 10.02.20 / МГОУ. - Москва, 2012. - 336 с.

16. Молодец И.И. Способы номинации в современном русском языке (на материале фотолексики) диссертация ... кандидата филологических наук : 10.02 .01 / Ин-т русского языка. - Москва, 1990. - 156 с.

17. Новодранова В.Ф. Именное словообразование в латинском языке и его отражение в терминологии. Laterculi vocum Latinarium et terminoruv / Poc. академия наук; Ин-т языкознания. МГМСУ. М.: Языки славянских культур, 2008. - 328 с. - (Studia philological).

18. Плещинская А.И. Развитие префиксоидного словообразования в русском языке: (на материале слов с элементами аудио-, видео-, кино-, фото. . . ) диссертация ... кандидата филологических наук: 10.02.01 / Казан. гос. ун-т им. В. И. Ульянова-Ленина. - Казань, 2005. - 166 с.

19. Сахаров А.А. Англо-русский словарь по фотографии и кинематографии / под ред. Е.М. Голдовского. М.: Гл. ред. иностранных науч.-технических слов. ФИЗМАТГИЗА, 1960. - 395 с.

20. Соловьева Н.М. Фотоаппаратура и ее эксплуатация: учеб. Пособие. М.: Дрофа, 2009. 286 с.

21. Тененёва И.В. Терминология фотографической техники: проблемы и принципы упорядочения: монография / И.В. Тененёва; Юго-Зап. гос. ун-т. - Курск, 2019. $-156 \mathrm{c}$.

22. Ткачева Л.Б. Основные закономерности английской терминологии. Томск: Томский государственный университет, 1987. - 200 с.

23. Чибисов К.В. Очерки по истории фотографии. Монография. М.: Искусство, 1987. - 255 с.

24. Cambridge [Электронный ресурc]. URL: https://dictionary.cambridge.org/ (дата обращения: 20.10.2020).

25. Longman [Электронный ресурc]. URL: https://www.Idoceonline.com/ (дата обращения: 20.10.2020).

26. Meriam-Webster [Электронный ресурc]. URL: https://www.merriam-webster.com/dictionary/ (дата обращения: 20.10.2020).

27. Multitran [Электронный ресурc]. URL: https://www.multitran.com/ (дата обращения: 20.10.2020).

28. The Free Dictionary by Farlex [Электронный ресурс]. URL: https://www.thefreedictionary.com/ (дата обращения: 20.10.2020).

(с) Кондратьева Ольга Анатольевна (li-photo@yandex.ru).

Журнал «Современная наука: актуальные проблемы теории и практики»

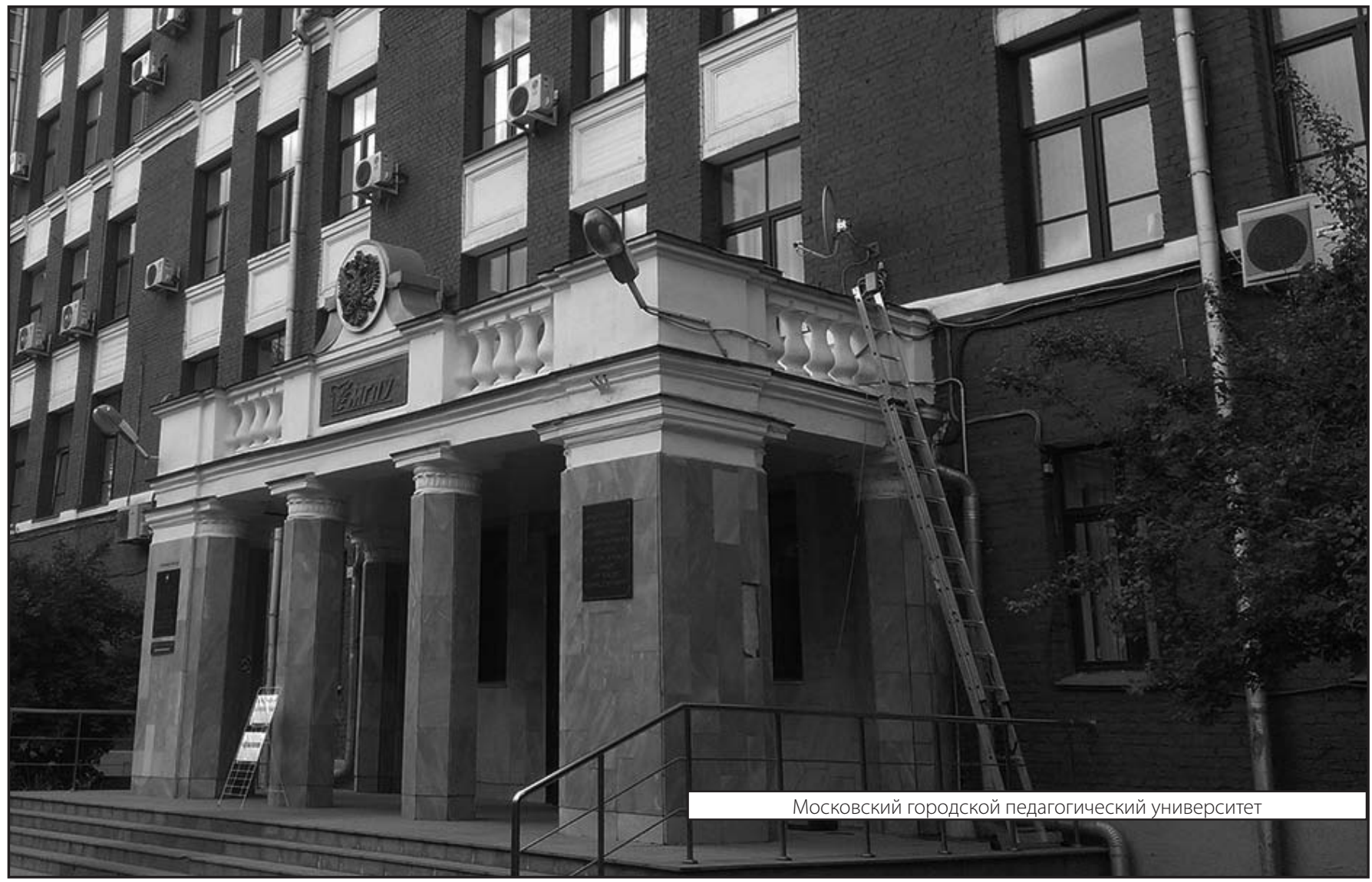

